$6^{\text {th }}$ International Conference on Hydroinformatics - Liong, Phoon \& Babovic (eds)

(C) 2004 World Scientific Publishing Company, ISBN 981-238-787-0

\title{
SENSITIVITY ANALYSIS OF FLOODPLAIN ROUGHNESS IN 1D FLOW
}

\author{
FREDRIK HUTHOFF \\ Water Engineering \& Management, Faculty of Engineering Technology, \\ University of Twente, PO-box 217, 7500 AE Enschede, The Netherlands \\ HKV consultants, PO-box 2120, 8203 AC Lelystad, The Netherlands \\ DENIE AUGUSTIJN \\ Water Engineering \& Management, Faculty of Engineering Technology, \\ University of Twente, PO-box 217, 7500 AE Enschede, The Netherlands
}

Towards the realization of appropriate modeling of vegetation roughness for river management purposes, a sensitivity analysis was carried out in order to identify the dominant parameters on predicted water levels. Based on 1D theoretical considerations and 1D numerical calculations, hydraulic properties of a simple prismatic channel were examined in relation to changing floodplain roughness, relative floodplain width and the trajectory length of roughened floodplain. It is shown that water level rise is most sensitive to changes in floodplain width if the original floodplain width is comparable in size to the width of the main channel. For changes in the trajectory length of the roughened floodplain, a rough absolute range was identified where sensitivity on resultant water levels is significant.

\section{INTRODUCTION}

In the modern vision on river basin management there is more attention for natural processes. In many countries solutions for flood defence are combined with nature rehabilitation to restore the ecological corridor function of river floodplains. Nature development however generally leads to an increase in roughness of the floodplain and consequently in a rise of the water level during flood events (when the floodplains contribute to the flow area). To evaluate the effect of changing roughness on flood levels it is important to describe the roughness adequately.

In most hydraulic models vegetation roughness is described by a bulk parameter, such as an average Chèzy or Nikuradse coefficient. To date, several studies have managed to relate physical vegetation parameters (stem width, amount of foliage, flexibility, average height, density, etc.) and the spatial coverage of vegetation to hydraulic resistance effects (e.g. [1][2][3][5][6][7]). Although the utilisation of a roughness coefficient based on physical plant parameters may be physically more correct, it may also introduce additional uncertainties due to natural variability and experimental error. The most appropriate method to describe vegetation roughness can only be 
determined when it is clear what the relative sensitivity is of changes in roughness on predicted flood levels.

The current study aims at showing the relevance of floodplain characteristics in determining the maximum water levels during flood conditions. For this purpose a 1D hydraulic model (SOBEK [8]) was used to perform a sensitivity analysis on a compound prismatic channel. Parameters that were investigated on their relative influence include (i) cross-section geometry (width and height), (ii) floodplain roughness, and (iii) the trajectory length of the roughened floodplain. Before the numerical results are presented, some basic theoretical considerations are given. These theoretical considerations will impose limits on the expected results from the numerical approach.

\section{THEORETICAL CONSIDERATIONS}

\section{Momentum balance in one dimension (1D)}

3D mechanisms are present in all types of flows. If the geometry of a system is of a sufficient simple form (straight channel with constant slope, width \& depth) then the flow can often satisfactorily be represented by a 1D description. Assuming uniform and stationary flow with a vertical logarithmic velocity profile, Chèzy's law describes the balance between frictional resistance and the weight of the fluid as:

$Q=A \bar{u}=A C \sqrt{R i}$

where $Q$ is the discharge, $\bar{u}$ the average flow velocity, $i$ the slope and $C$ a measure for the resistance (Chèzy's coefficient).

A consequence of such an approach is that the shape of the cross-section is not explicitly included but represented by a cross-section area $(A)$ and a hydraulic radius $(R$, the ratio between $A$ and the wetted perimeter $P$ ). Likewise, the roughness of the complete cross-section needs to be characterized by a bulk value. Different approaches have been proposed for constructing a bulk composite roughness value (see [4] and the references cited therein). Here, the composite roughness method as incorporated in the SOBEK hydraulic simulation package is followed [8]. SOBEK is also used for the numerical investigation in the present study.

\section{Composite roughness for simple cross-section geometry}

In constructing the composite roughness it is assumed that in each river section the uniform flow formula is valid, no lateral surface slope arises and that discharges in different subsections add up to the total discharge, i.e. in each subsection Chèzy's law is satisfied:

$$
Q_{\text {comp }}=Q_{m}+Q_{f} \Rightarrow A_{\text {comp }} C_{\text {comp }} \sqrt{R_{\text {comp }} i}=A_{m} C_{m} \sqrt{R_{m} i}+A_{f} C_{f} \sqrt{R_{f} i}
$$

where subscript $m$ refers to the main channel and $f$ to the floodplain subsection. 




Figure 1. Definitions of geometrical parameters in a simple compound cross-section.

For a simple geometry (such as shown in Figure 1) cross-sections and hydraulic radii of the different sections can be expressed in terms of large-scale geometrical parameters. Here two dimensionless geometrical parameters are used: the parameter $\alpha$ is defined as the ratio between the main channel width $\left(W_{m}\right)$ and the total width $\left(W_{T}\right.$, including the floodplains on both banks), and parameter $\beta$ as the ratio between the water depth in the floodplains $(h)$ and the channel depth of the main flow section $\left(D_{m}\right)$. In terms of the geometrical parameters $\alpha$ and $\beta$, the expression for composite roughness in a composite rectangular channel yields:

$C_{\text {comp }}=\alpha\left(\frac{1+1 / \beta}{1+\alpha / \beta}\right)^{3 / 2} C_{m}+(1-\alpha)\left(\frac{1}{1+\alpha / \beta}\right)^{3 / 2} C_{f}$

In deriving Eq. (3) it is assumed that the wetted perimeter is equal to the width of the subsection (the vertical wetted part is negligible compared to horizontal wetted part).

\section{Water level rise due to increase of (composite) roughness}

The maximum effect on the water level for a changing composite roughness can be estimated by equating the discharge between two uniform stationary situations. Assume that for a given discharge the composite roughness $C_{\text {comp }}$ results in a water level $h$ in the floodplain and that roughness $C^{\prime}{ }_{\text {comp }}$ results in an increased water level in the floodplain of $h+\Delta h$ (corresponding to the rougher case). Eq. (4) gives the estimated relative water level difference between the two situations.

$\frac{\Delta h}{h}=(1+\alpha / \beta)\left(\left(C_{\text {comp }} / C_{\text {comp }}^{\prime}\right)^{2 / 3}-1\right) \quad C_{\text {comp }} \geq C_{c o m p}^{\prime}$ 
Prismatic channel Total length: $100 \mathrm{~km}$ Slope: $0.01 \%$

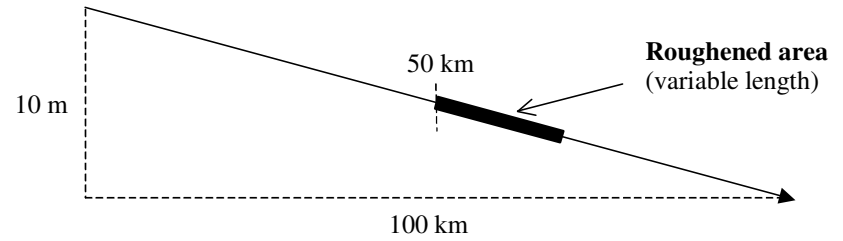

Figure 2. Straight river branch used for numerical simulation

\section{Dependencies}

In the preceding sections it was demonstrated that the relative water level rise has the dependencies $\Delta h / h=f\left(\alpha, \beta, C_{\text {comp }} / C^{\prime}{ }_{\text {comp }}\right)$ where the composite roughness depends on $C_{\text {comp }}=f\left(\alpha, \beta, C_{f}, C_{m}\right)$. It appears as if the relative geometrical ratios $\alpha$ and $\beta$ are the relevant parameters when studying the influence of floodplain roughness, not the absolute dimensions of the cross-section. This hypothesis will be further examined in the following numerical sensitivity analysis. In the numerical calculations the effect of longitudinal changes (parallel to direction of flow) in floodplain properties will also be considered.

\section{SENSITIVITY ANALYSIS: 1D NUMERICAL SIMULATIONS}

Figure 2 shows a rough sketch of the river branch model that was used for the 1D numerical simulations. The total length of the branch is $100 \mathrm{~km}$ with a constant slope of $0.01 \%$. The slope corresponds to a drop of $10 \mathrm{~m}$ over a traveled distance of $100 \mathrm{~km}$, which is a representative value for typical lowland rivers. The geometry of the crosssection remains constant along the branch. Halfway through the traveled distance (at $\mathrm{km}$ 50), the region starts where floodplain roughness may be increased.

The roughness in the floodplain will be characterized by a Nikuradse parameter $k$. A simple logarithmic relation transfers $k$ to $C_{f}\left(C_{f}=18 \log (12 h / k)\right)$. In Table 1 the geometries and values for the roughness parameters used in the numerical simulations are given. Note that $C_{f}$ is dependent on the water level, while $C_{m}$ (in the main channel) is taken as a constant value. A reference floodplain roughness of $k=0.25 \mathrm{~m}$ and a main channel resistance of $C_{m}=45 \mathrm{~m}^{1 / 2}$ s were used along the complete trajectory of the channel.

A total number of 12 reference cases were calculated composed of the different geometries (4 floodplain widths and 3 main channel widths). For each geometry, the discharge that results in the floodplain water level of $h=1 \mathrm{~m}$ was determined. Next, these discharges were used to calculate the water level for increased roughness values $(k=0.5$, $1,2$ and $4 \mathrm{~m})$ over 4 different trajectory lengths $(l=2.5,5,10$ and $20 \mathrm{~km})$. 
Table 1. Used geometry and roughness values for numerical sensitivity analysis.

\begin{tabular}{|l|c|r|r|}
\hline \multicolumn{2}{|c|}{ Parameter } & Reference value & \multicolumn{1}{c|}{ Variable values } \\
\hline Depth main channel & $D_{m}$ & $5 \mathrm{~m}$ & \\
Water depth in floodplain & $h$ & $1 \mathrm{~m}$ & \\
\hline Width main channel & $W_{m}$ & & $125,250,500 \mathrm{~m}$ \\
Width floodplain & $W_{f}$ & & $250,500,1000,2000 \mathrm{~m}$ \\
Roughened area (length) & $l$ & & $2.5,5,10,20 \mathrm{~km}$ \\
\hline Resistance main channel & $C_{m}$ & $45 \mathrm{~m}^{1 / 2} \mathrm{~s}$ & $0.5,1,2,4 \mathrm{~m}$ \\
Floodplain roughness & $k$ & $0.25 \mathrm{~m}^{1}$ & \\
\hline
\end{tabular}
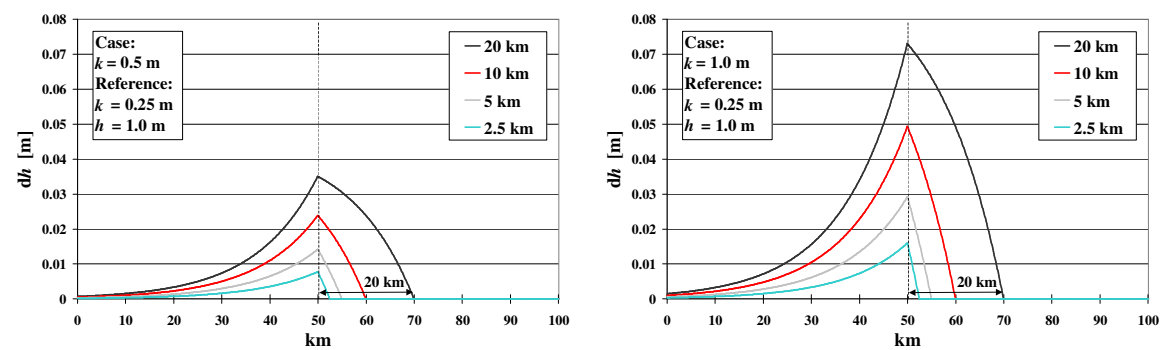

Figure 3. Change of water levels in the floodplain for different cases of partial roughening of floodplain in the longitudinal direction. The cross-section geometry used is: $W_{f}=250 \mathrm{~m}$ and $W_{m}=125 \mathrm{~m}(\alpha=1 / 3)$.

\section{Maximum water level rise}

In Figure 3 the effect of increasing roughness of the floodplain is shown. As expected, a longer stretch of roughened floodplains results in a larger increase in the water level (water level rise is non-linear with respect to roughened trajectory length $l$ ). Note also that the maximum increase of water level always occurs at the point along the river where roughening starts. The water level in the floodplain at this point will be used in the remainder of the analysis.

\section{Scaling effects on water level rise in floodplain}

Before the actual influences of floodplain properties on the water level rise are considered, some scaling properties of the system will be examined. For this purpose, results are compared between numerical calculations in which (cross-section) geometries have a difference of factor 4 in width. The compared geometries are shown in Table 2.

\footnotetext{
${ }^{1}$ Reference floodplain roughness is used along the complete length of the river branch, except in the area with increased floodplain roughness (the trajectory beyond $\mathrm{km} \mathrm{50,} \mathrm{see} \mathrm{Figure} \mathrm{2).}$
} 
Table 2. Cross-section geometries considered for investigation of scaling effects.

\begin{tabular}{|c|r|r|r|c|c|r|r|r|c|}
\hline Case & $\begin{array}{r}W_{T} \\
{[\mathrm{~m}]}\end{array}$ & $\begin{array}{r}W_{f} \\
{[\mathrm{~m}]}\end{array}$ & $\begin{array}{r}W_{m} \\
{[\mathrm{~m}]}\end{array}$ & $\begin{array}{c}\alpha \\
W_{m} / W_{T}\end{array}$ & Case & $\begin{array}{r}W_{T} \\
{[\mathrm{~m}]}\end{array}$ & $\begin{array}{r}W_{f} \\
{[\mathrm{~m}]}\end{array}$ & $\begin{array}{r}W_{m} \\
{[\mathrm{~m}]}\end{array}$ & $\begin{array}{c}\alpha \\
W_{m} / W_{T}\end{array}$ \\
\hline 1 & 375 & 250 & 125 & $1 / 3$ & 3 & 625 & 500 & 125 & $1 / 5$ \\
2 & 1500 & 1000 & 500 & $1 / 3$ & 4 & 2500 & 2000 & 500 & $1 / 5$ \\
\hline
\end{tabular}
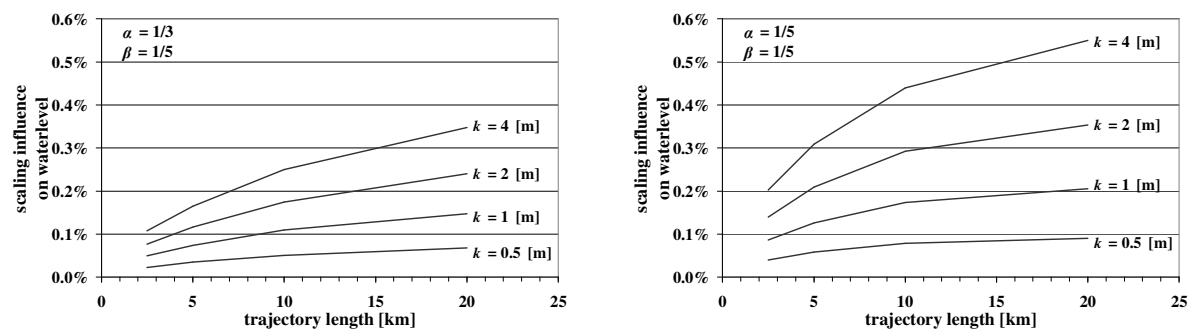

Figure 4. Differences in water level rise between situations where the total width of the cross-section differ a factor 4. By "scaling influence on water level" is meant the change in relative water level rise.

Four specific situations are considered: two with main to total width ratio (parameter $\alpha$ ) of $1 / 5$ and two with a ratio of $1 / 3$. In Figure 4 differences in water level rise between cases with equal geometrical parameters $\alpha$ and $\beta$ are shown.

In Figure 4 the graph on the left corresponds to $\alpha=1 / 3$, where the difference between water level rise in case 1 and 2 (Table 2) is compared. The figure shows a difference in water level rise of $0.15 \%$ if floodplain roughness is $k=1$ over a length of $20 \mathrm{~km}$. In Figure 3 (right graph) it can be seen that this specific case yields an absolute water level rise of around $7 \mathrm{~cm}$. Therefore, a channel with equal geometrical parameters $\alpha$ and $\beta$, but different absolute width (factor 4) results in a difference in water level rise of $0.15 \%$ of 7 $\mathrm{cm}$ (which amounts to an absolute difference of roughly $0.01 \mathrm{~cm}$ ). Likewise, the right graph in Figure 4 shows the difference in water level rise between cases 3 and 4 . It follows that larger relative floodplain widths (decreasing $\alpha$ ) result in larger errors regarding the equivalence of situations with different absolute size. Nevertheless, even in the case where $\alpha=1 / 5$ the difference in water level rise after channel widening with a factor 4 is not more than a few mm. This means that parameter $\alpha$ characterizes the dependency of horizontal geometry on water level rise very well. 

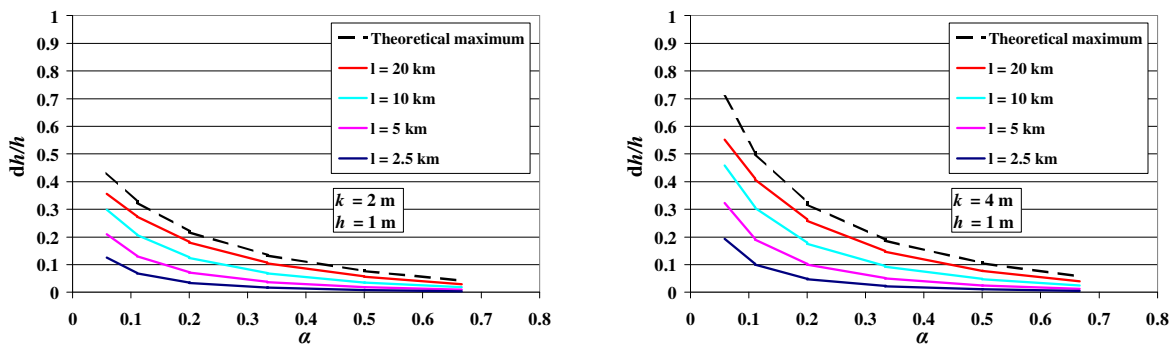

Figure 5. The influence of geometry alterations on the relative water level rise in the floodplain. The dashed line denotes the theoretical maximum water level rise (Eq. 5).

\section{Relative water level rise as a function of $\alpha$}

Figure 5 shows the dependency of the relative water level rise due to floodplain roughening as a function of parameter $\alpha$. The left graph shows results for an increase of floodplain roughness from $0.25 \mathrm{~m}$ (reference case) to $k=2 \mathrm{~m}$, and the right graph for floodplain roughening to $k=4 \mathrm{~m}$. Larger relative floodplain widths (smaller $\alpha$ ) result in larger increases in water level rise when floodplain roughening occurs. In each graph also the theoretical maximum water level rise (Eq. 4) is included (represented by dashed line). Under the used flow conditions, a roughened floodplain of length $20 \mathrm{~km}$ increases the water level to at least $80 \%$ of the theoretical maximum (corresponding to floodplain roughening of infinite length).

Figure 5 also shows that $\Delta h / h$ is steepest for small values of $\alpha$. However, if $\alpha$ changes from, say, 0.2 to 0.1 , the corresponding floodplain width changes from 4 to 9 times the main channel width. A similar change in $\Delta h / h$ occurs between $\alpha=0.5$ and 0.3 , where the floodplain width changes from a width equal to that of the main channel to a width just over twice that value. Water level rise is therefore most sensitive to changes in floodplain width if the floodplain width is comparable in size to the width of the main channel.

\section{CONCLUSIONS}

Theoretical considerations suggest that the relative floodplain width $(\alpha)$ and the relative water level in the floodplain $(\beta)$ are suitable parameters for describing effects of floodplain roughening. Numerical calculations support the case for relative floodplain width: scaling the width of the system by a few factors has negligible effects on the water level rise (under equal flow conditions). Furthermore, it was shown that water level rise is most sensitive to changes in floodplain width if the original floodplain width is comparable in size to the width of the main channel

In the numerical calculations also the effect of changing the (longitudinal) length of the floodplain was investigated. Longer roughened floodplains lead to larger increases of 
water level, eventually converging towards a maximum possible water level rise. At a length of $20 \mathrm{~km}$ an increase in water level is reached that exceeds $80 \%$ of the maximum attainable rise. Therefore, water level rise is very insensitive to trajectory length changes if the roughened floodplain is much larger than $20 \mathrm{~km}$. A point of interest for future work is the identification of a more general criterion that indicates the relative influence of changes in trajectory length on water levels.

The current work relies entirely on flow in the 1D case, thereby neglecting lateral and vertical effects that occur in realistic $3 \mathrm{D}$ situations. The effect of roughness in $2 \mathrm{D}$ simulations and the use of other roughness parameters is currently being investigated. From a 2D approach it will become clear whether the composite roughness approach used here is a valid assumption. Also, based on the theoretical considerations it appears as if the ratio between Chèzy roughness of the main channel and floodplain is a suitable parameter for describing the relative water level rise in terms of relative roughness increase.

\section{ACKNOWLEDGEMENTS}

We would like to thank the German Federal Institute of Hydrology (BfG) for their support in partly financing the current research.

\section{REFERENCES}

[1] Freeman G.E., Rahmeyer W.J. and Copeland R.R., "Determination of resistance due to shrubs and woody vegetation”, U.S. Army Engineer Research and Development Center, Vicksburg MS, (2000).

[2] Järvelä J., "Flow resistance of flexible and stiff vegetation: a flume study with natural plants", Journal of Hydrology, Vol. 269, (2002), pp 44-54.

[3] Klopstra D., Barneveld H.J., van Noortwijk J.M. and van Velzen E.H., “Analytical model for hydraulic roughness of submerged vegetation”, Proc. Managing Water: Coping with scarcity and abundance, San Francisco, (1997), pp 775-780.

[4] Knight, D.W. and Shiono K., "River channel and floodplain dynamics", In: Floodplain Processes, (Eds. Anderson, Walling \& Bates), Chapter 5, J Wiley, (1996), pp 139-181.

[5] Kouwen, N. and Fathi-Moghadam M., "Friction factors for coniferous trees along rivers", Journal of Hydraulic Engineering, Vol. 126, No. 10, (2000), pp 732-740.

[6] Stephan U. and Gutknecht D., "Hydraulic resistance of submerged flexible vegetation", Journal of Hydrology, Vol. 269, (2002), pp 27-43.

[7] Wilson C.A.M.E., Stoesser T., Bates P.D. and Batemann Pinzen A., "Open channel flow through different forms of submerged flexible vegetation", Journal of Hydraulic Engineering, Vol. 129, No. 11, (2003), pp 847-853.

[8] WLI Delft Hydraulics and RIZA (Institute for Inland Water Management and Waste Water Treatment), “SOBEK River/Estuary”, Version 2.52, (2003). 